\title{
Extreme warming restructures habitat distribution and productivity along local gradients in stress and biodiversity
}

\author{
Matthew Whalen ${ }^{1}$, Sam Starko ${ }^{1}$, Sandra Lindstrom ${ }^{1}$, and Patrick Martone ${ }^{1}$ \\ ${ }^{1}$ The University of British Columbia
}

May 25, 2021

\begin{abstract}
Significant questions remain about how ecosystems that are structured by abiotic stress will be affected by climate warming. A well-supported hypothesis states that warming will cause species to shift along abiotic gradients, such that distributions track changing local conditions. Here, we investigated the impacts of a multi-year heatwave on community dynamics and zonation in one such ecosystem: rocky intertidal communities. We demonstrate that, while populations generally shifted downslope towards reduced abiotic stress, species were impacted to varying degrees, leading to complex changes in community and ecosystem dynamics. Warming generally shifted primary production away from upper elevations through synchronized seaweed declines and replacement by invertebrates, while high producer biomass was maintained at lower elevations through compensatory dynamics that resulted in novel community composition. Our results illustrate that, rather than shifting community zonation uniformly along local gradients, warming will restructure habitat archetypes and redirect pathways for energy transfer in stress-structured systems.
\end{abstract}

\section{Hosted file}

Calvert_intertidal_MS_submit_text.docx available at https://authorea.com/users/415593/ articles/523436-extreme-warming-restructures-habitat-distribution-and-productivityalong-local-gradients-in-stress-and-biodiversity 


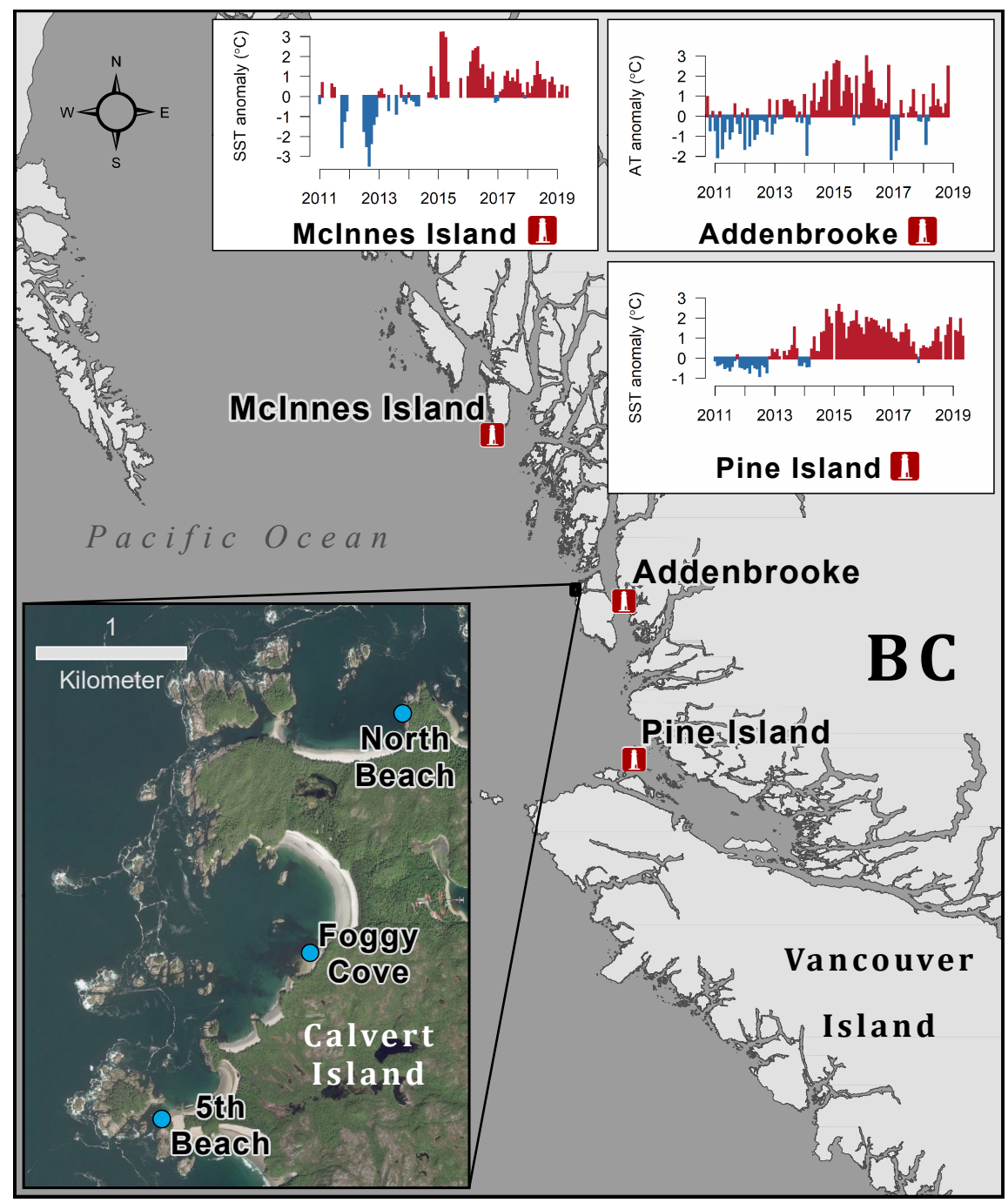

\section{Hosted file}

Fig2.svg available at https://authorea.com/users/415593/articles/523436-extreme-warmingrestructures-habitat-distribution-and-productivity-along-local-gradients-in-stress-andbiodiversity

\section{Hosted file}

Fig3.svg available at https://authorea.com/users/415593/articles/523436-extreme-warmingrestructures-habitat-distribution-and-productivity-along-local-gradients-in-stress-andbiodiversity

\section{Hosted file}

Fig4.svg available at https://authorea.com/users/415593/articles/523436-extreme-warmingrestructures-habitat-distribution-and-productivity-along-local-gradients-in-stress-andbiodiversity 

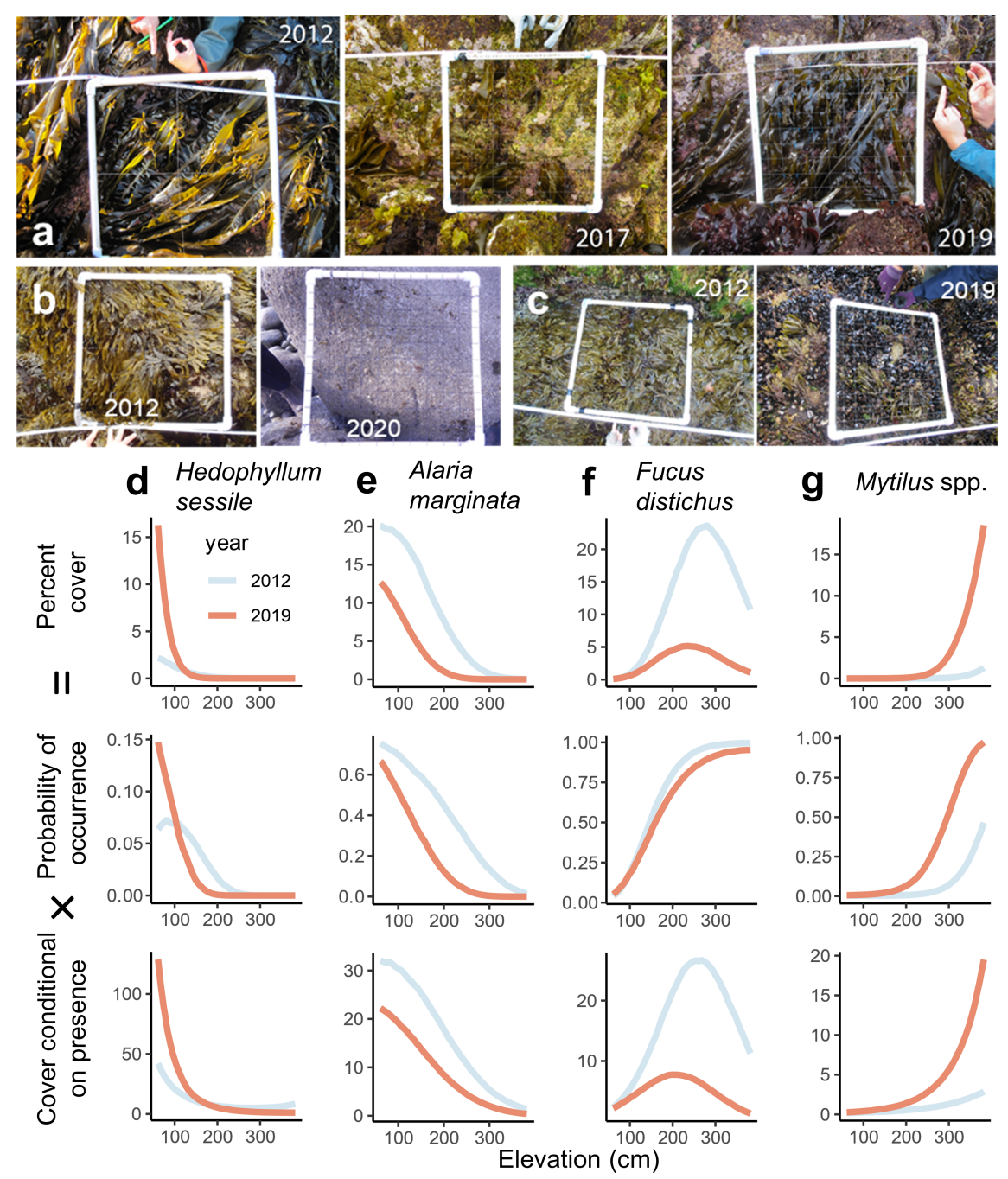